\title{
Smoking prevalence, attitudes and associated factors among students in health-related Departments of Community College in rural Yemen
}

\author{
Abdulsalam M.A. Nasser', Bassam A.M. Salah', Luba T. Regassa', Abdulrakeeb A.S. Alhakimy', Xinping Zhang ${ }^{1}$
}

\section{ABSTRACT}

INTRODUCTION Tobacco smoking is a global concern and tobacco use is rising among the youth in Arab countries, such as Yemen, especially among university students. This study aims to examine the prevalence, attitudes and associated factors of smoking among college students in the rural area of Hajja, Yemen.

METHODS A cross-sectional descriptive study was conducted at a community college in the Hajja province between August and December 2016. The data were collected from three health related departments (Nursing, Laboratory, and Assistant doctor). A questionnaire based on the Global Health Professional Survey and the Global Youth Tobacco Survey was answered by 380 randomly selected students.

RESULTS Logistic regression analyses indicated that $\operatorname{sex}(\mathrm{OR}=0.4,95 \% \mathrm{CI}$ : $0.2-0.8, \mathrm{p}<0.05)$, family income $(\mathrm{OR}=2.0,95 \% \mathrm{CI}: 1.2-3.3, \mathrm{p}<0.05)$, and residence $(\mathrm{OR}=0.2,95 \%$ CI: $0.1-0.5, \mathrm{p}<0.001)$, were statistically significant predictors of smoking. Smoking for peer pressure, recreation and proving manhood were all found to be highly significant $(\mathrm{p}<0.001)$. The results also revealed that smokers had more negative attitudes towards allowing children to smoke in the future and allowing smoking in the household $(\mathrm{p}<0.001)$.

conclusions Compared to similar studies on the general population, the prevalence of smoking among college students in the rural area was lower. An indication of a growth in tobacco use can be concluded, accordingly, the need for anti-smoking programmes to prevent students from initiating smoking is required.
ABBREVIATIONS WHO: World Health Organization, GATS: Global Adult Tobacco Survey, GYTS: Global Youth Tobacco Survey, GNI: Gross National Income, SPSS: Statistical Package for the Social Sciences, US: United States, KSA: Kingdom of Saudi Arabia, UAE: United Arab Emirates, HUST: Huazhong University of Science and Technology.

\author{
AFFILIATION \\ 1 School of Medicine and Health \\ Management, Tongji Medical \\ Collage, Wuhan, China \\ 2 Institute of Urology, Department \\ of Urology, The First Affiliated \\ Hospital of China Medical \\ University, Shenyang, China \\ CORRESPONDENCE TO \\ Xinping Zhang. School of Medicine \\ and Health Management, Tongji \\ Medical Collage, (HUST), Wuhan, \\ Hubei 430030, China. \\ E-mail: xpzhang602@163.com \\ KEYWORDS \\ smoking, attitudes, associated \\ factors, rural area, Yemen
}

Received: 21 July 2017 Revised: 24 June 2018 Accepted: 24 June 2018

\section{INTRODUCTION}

Smoking is a leading cause of preventable morbidity and mortality worldwide. Tobacco smoking causes annually 6 million deaths worldwide and is projected to exceed 8 million by 2030, according to statistics from the World Health Organization (WHO) ${ }^{1}$. Smoking was identified as the most important cause of preventable morbidity and premature death ${ }^{2}$. This ratio is estimated to increase to 10 million in $20-30$ years. Due to tobacco use, the morbidity rate is $70 \%$ in developing countries, and these countries are the ones in which problems due to epidemic tobacco use are mostly seen ${ }^{3-5}$.

The WHO estimates the number of smoking 
individuals as 1.1 billion, globally. A total of 700 million male smokers are located in developing countries, and $47 \%$ of men and $12 \%$ of women smoke a total of 6 trillion cigarettes a year worldwide ${ }^{5}$. According to the Global Youth Tobacco Survey (GYTS) conducted in 2001, in five Arab countries in the Middle East, approximately $10 \%$ of youths (13-15 years of age) use different kinds of tobacco products ${ }^{6}$.

On the other hand, a recent study on smoking among Arab-American adolescents found that $26.6 \%$ of the studied sample smoked waterpipes ${ }^{7}$, emphasizing the increasing trend of this form of smoking among Arab youths. In Lebanon and Jordan, studies have reported that the prevalence of waterpipe smoking was more common than cigarette smoking among university students $\mathrm{s}^{8,9}$.

A household survey conducted by the WHO in some Arab countries in 2012 stated that the prevalence of smoking any tobacco product among those aged $\geqslant 15$ years in 2009 was $24 \%$ and $1 \%$ in the KSA, $46 \%$ and $31 \%$ in Lebanon, $47 \%$ and $6 \%$ in Jordan, $35 \%$ and $4 \%$ in Kuwait, $34 \%$ and $8 \%$ in Bahrain, $58 \%$ and $5 \%$ in Tunisia, and $35 \%$ and $11 \%$ in Yemen, among males and females, respectively ${ }^{10}$. Based on the Global Adult Tobacco Survey (GATS) conducted on the population aged $\geqslant 15$ years in Qatar in 2013, the results indicated that the prevalence of waterpipe use was $4.9 \%$ and $1.6 \%$ among males and females, respectively ${ }^{11}$. On the other hand, a report from the WHO on the global tobacco epidemic, conducted on the population aged 15 years or more in Yemen in 2017 concluded that the estimated prevalence of smoking was $18.7 \%$ among both sexes ${ }^{12}$.

However, the prevalence of smoking, especially among university students, is largely unknown in many of these Arab countries, including Yemen, and to the best of our knowledge, no student-based survey has been conducted on the prevalence of smoking and its associated factors in the rural area of Hajja, Yemen.

The goal of the study is to determine the ratio, attitudes and associated factors of smoking among college students in the rural area of Hajja, Yemen.

\section{METHODS}

A cross-sectional descriptive study was done during the winter course of the 2016 academic year upon the approval from the review board of the community college located in the Hajja province of Yemen. A self-administered, anonymous questionnaire about smoking, attitudes and associated factors was completed by college students in three different health-related departments of the community college (Nursing, Laboratory, and Assistant doctor).

\section{Sample}

The community college has seven departments. All three health-related departments namely Nursing, Laboratory, and Assistant doctor were purposively selected. We aimed to recruit $>35 \%$ from the total 1093 students registered at these three healthrelated departments in 2016 , based on the total number of students in each department of not equal size; the sample from each department was chosen to represent proportionately the total number of students in that department. Hence, about 400 (36.6\%) students were randomly selected and invited to take part in the survey. All 400 students approached agreed to complete the questionnaire, yielding a response rate of $100 \%$. Due to incorrect filling in, 20 questionnaires were discarded and a total of 380 (response rate $95 \%$ ) were analysed.

\section{Data collection}

Questionnaire forms were delivered to students in their classrooms during breaks and were collected as soon as they were completed. Students had been informed that questionnaire participation was voluntary, their identity would not be recorded on the form, all the data in the questionnaire would be used for research purposes, and no penalty would be applied against non-participants.

The questions gathered information about basic demographic properties and issues regarding tobacco usage, including participants' points of view, smoking behaviours, habits and attitudes. The questionnaire was in Arabic and English, and derived from models based on the Global Youth Tobacco Survey ${ }^{13}$ and Global Health Professional Survey ${ }^{14}$.

The first items ( sociodemographic profile) covered sex, age, type of college, marital status, residence, grade, family economic situation and smoking style (both cigarette and waterpipe). This was followed by questions about attitudes and beliefs concerning smoking (smoking or not, smoking reasons, allowing children to smoke in the future, prohibiting smoking at home, and prohibiting it in public areas). 


\section{Definition}

Smoking status was established in accordance with the WHO criteria for cigarette smoking and the criteria set by Maziak et al. for waterpipe smoking ${ }^{15,16}$. Smokers in this survey referred to subjects who at the time of the survey smoked either regularly one cigarette/day or more, or one waterpipe/week. Nonsmokers were defined as students who never smoked one cigarette in their lifetime and who did not smoke at all during the time of the survey.

According to World Bank's country and lending categorizations (2016), Yemen ${ }^{17}$ was in the lowermiddle-income economies with a Gross National Income (GNI) per capita per year of US\$1006-3955. Therefore, the family income item was categorized into low (US $\$<100 /$ month), middle (US $\$>100$ $200 /$ month) and high (US\$ $>200-300 /$ month).

\section{Statistical analysis}

The computer package SPSS version 20 was used for data analysis. Data were presented as numbers and percentages, and were compared using a chisquared test. Logistic regression was also applied to investigate the relationship between tobacco usage and the socio-economic factors such as sex, age, marital status, study level, residence, income and college. The results based on $p$-value varied between highly significant, significant and not significant. Significance was considered for $\mathrm{p}<0.05$.

\section{RESULTS}

\section{Characteristics of the samples}

This study included a total of 380 students; 234 (61.6\%) were males and 146 were females $(38.4 \%)$. More than (76.1\%) were aged from 18 to 24 years. The mean age was $21.43 \pm 2.27$ years. Most of the participants were in the department of Nursing (43.4\%), followed by the department of Laboratory (32.4\%) and the department of Assistant doctor $(24.2 \%)$. Most students were married $(84.2 \%)$ and living with their parents $(73.9 \%)$. About $54.5 \%$ of the students were from low-income families.

The prevalence of smoking was higher among students who were living in dormitories than those who were living with their families $(23.2 \%$ vs $8.5 \%$, p $<0.001)$. Similarly, it was higher among students from low-income families compared to those from average and high-income ones $(15.9 \%, 10.8 \%$ and $3.2 \%$, respectively, $\mathrm{p}<0.05)$ (Table 1$)$.

Table 1. Smoking status of the study sample based on the demographic characteristics in the rural area ( $\mathrm{N}=380)$

\begin{tabular}{|c|c|c|c|c|c|c|}
\hline Characteristics & $\begin{array}{c}\text { Total } \\
\text { n }\end{array}$ & $\begin{array}{c}\text { Per cent } \\
(\%)\end{array}$ & $\begin{array}{c}\text { Smokers } \\
\text { n }(\%)\end{array}$ & $\begin{array}{c}\text { Von-smokers } \\
\text { n (\%) }\end{array}$ & $x^{2}$ & $p$ \\
\hline \multicolumn{7}{|l|}{ Age (years) } \\
\hline$<18$ & 49 & 12.9 & $5(10.2)$ & 44 (89.8) & 0.688 & 0.747 \\
\hline $18-24$ & 289 & 76.1 & $38(13.1)$ & 251 (86.9) & & \\
\hline Over 24 & 42 & 11.1 & $4(9.5)$ & $38(90.5)$ & & \\
\hline \multicolumn{7}{|c|}{ College Department } \\
\hline Nursing & 165 & 43.4 & 23 (13.9) & $142(86.1)$ & 0.677 & 0.719 \\
\hline Laboratory & 123 & 32.4 & $14(11.4)$ & 109 (88.6) & & \\
\hline Assistant Doctor & 92 & 24.2 & 10 (10.9) & $82(89.1)$ & & \\
\hline \multicolumn{7}{|l|}{ Marital status } \\
\hline Married & 320 & 84.2 & $39(12.2)$ & 281 (87.8) & 0.061 & 0.831 \\
\hline Single & 60 & 15.8 & $8(13.3)$ & $52(86.7)$ & & \\
\hline \multicolumn{7}{|l|}{ Study level } \\
\hline First-year & 269 & 70.8 & $28(10.4)$ & 241 (89.6) & 4.289 & 0.118 \\
\hline Second-year & 54 & 14.2 & $11(20.4)$ & $43(79.6)$ & & \\
\hline Third-year & 57 & 15.0 & $8(14.0)$ & $49(86.0)$ & & \\
\hline \multicolumn{7}{|l|}{ Residence } \\
\hline With family & 281 & 73.9 & $24(8.5)$ & 257 (91.5) & 14.578 & $<0.000$ \\
\hline Dormitory & 99 & 26.1 & $23(23.2)$ & $76(76.8)$ & & \\
\hline \multicolumn{7}{|c|}{ Family monthly income } \\
\hline Low & 207 & 54.5 & $33(15.9)$ & $174(84.1)$ & 7.469 & 0.022 \\
\hline Average & 111 & 29.2 & $12(10.8)$ & $99(89.2)$ & & \\
\hline High & 62 & 16.3 & $2(3.2)$ & $60(96.8)$ & & \\
\hline
\end{tabular}


The total prevalence of smoking among students was $12.4 \%$ (cigarettes $7.4 \%$ and waterpipe $5.0 \%$ ). No student reported to be a dual user of cigarettes and waterpipe. The prevalence of cigarette smoking among males was $10.3 \%$ and $2.7 \%$ for females, while the prevalence of waterpipe smoking among males was $0.0 \%$ and $13.0 \%$ among females $(\mathrm{p}<0.001)$.

Table 2 shows factors that were associated with being a smoker. The covariates examined were gender (female vs male), age $(<18,18-24$ years and over 24 years), study level (first, second and third year), marital status ( single vs married), family income (low, average, high), residence (dormitory vs family home) and college departments (Nursing,

Table 2. Relationship between demographic factors and smoking among college students in the rural area

$\begin{array}{lrrrrr}\text { Varriable } & \beta & \text { SE } & \text { Wald }-\chi^{2} & \text { P } & \text { OR }\left(95^{\circ} \text { CI }\right) \\ \text { Sex } & -0.883 & 0.345 & 6.554 & 0.010 & 0.4(0.2-0.8) \\ \text { Age } & 0.165 & 0.368 & 0.201 & 0.654 & 1.2(0.6-2.4) \\ \text { Marital status } & 0.235 & 0.466 & 0.254 & 0.614 & 1.3(0.5-3.2) \\ \text { Study level } & -0.258 & 0.214 & 1.455 & 0.228 & 0.8(0.5-1.2) \\ \text { Residence } & -1.453 & 0.351 & 17.187 & 0.000 & 0.2(0.1-0.5) \\ \text { Family income } & -0.676 & 0.268 & 6.349 & 0.012 & 2.0(1.2-3.3) \\ \text { College } & 0.117 & 0.218 & 0.287 & 0.592 & 1.1(0.7-1.7) \\ \text { departments } & & & & & \\ \beta: \text { estimated coefficient, SE: standard error, OR: odds ratio, Cl: confidence interval. }\end{array}$

Laboratory, Assistant doctors). There was a strong statistically significant association of smoking with residence $(p<0.001)$. Sex $(p<0.05)$ and family income $(p<0.05)$ were statistically associated with smoking. There was no significant association between the risk of smoking and age, marital status, College departments or study level. The logistic regression analysis indicated that females were less likely to be smokers $(\mathrm{OR}=0.4,95 \%$ CI: $0.2-0.8)$ and the respondents who lived with their family were also found less likely to be smokers ( $\mathrm{OR}=0.2,95 \%$ CI: 0.1-0.5). On the other hand, the lower family income appeared to be a risk factor of being a smoker (OR=2.0, 95\% CI: $1.2-3.3$ ).

Table 3 reveals the attitudes of smokers and nonsmokers towards different smoking styles and the prohibiting of indoor or outdoor smoking areas. Smokers had a positive attitude towards smoking compared to non-smokers $(100.0 \%$ vs $0.00 \%$, $\mathrm{p}<0.001)$. Analysing the reasons why students tend to smoke revealed a highly significant difference ( $p<0.001$ ); $15.7 \%$ of smokers versus $84.3 \%$ of nonsmokers thought that students smoke for recreational reasons, while $23.3 \%$ of smokers and $76.7 \%$ of nonsmokers believed that students may smoke because of peer pressure. Smokers appeared to have more

Table 3. Attitudes and beliefs concerning smoking among college students in rural areas $(\mathrm{N}=380)$

\begin{tabular}{|c|c|c|c|c|c|c|}
\hline Ilems & & & $\begin{array}{l}\text { Smokers } \\
\text { n ( }(\%)\end{array}$ & $\begin{array}{l}\text { Non-smokers } \\
\text { n ( }(\%)\end{array}$ & $x^{2}$ & $p$ \\
\hline \multicolumn{7}{|c|}{ Do you agree with smoking behaviour? } \\
\hline Yes & 18 & 4.7 & $18(100.0)$ & $0(00.0)$ & Fisher's exact & $<0.000$ \\
\hline No & 362 & 95.3 & $29(8.0)$ & $333(92.0)$ & & \\
\hline \multicolumn{7}{|c|}{ Why do students smoke? } \\
\hline Recreation & 121 & 31.8 & $19(15.7)$ & $102(84.3)$ & 34.171 & $<0.000$ \\
\hline Proving manhood & 52 & 13.7 & $0(00.0)$ & $52(100.0)$ & & \\
\hline Peer pressure & 120 & 31.6 & $28(23.3)$ & $92(76.7)$ & & \\
\hline Other reasons & 87 & 22.9 & $0(00.0)$ & $87(100.0)$ & & \\
\hline \multicolumn{7}{|c|}{$\begin{array}{l}\text { Would you allow smoking in your } \\
\text { household? }\end{array}$} \\
\hline Yes & 42 & 11.1 & $27(64.3)$ & $15(35.7)$ & 117.426 & $<0.000$ \\
\hline No & 338 & 88.9 & $20(5.9)$ & $318(94.1)$ & & \\
\hline \multicolumn{7}{|c|}{$\begin{array}{l}\text { Would you allow your children to } \\
\text { Smoke in the future? }\end{array}$} \\
\hline Yes & 18 & 4.7 & $14(77.8)$ & $4(22.2)$ & Fisher's exact & $<0.000$ \\
\hline No & 362 & 95.3 & $33(9.1)$ & 329 (90.9) & & \\
\hline \multicolumn{7}{|c|}{$\begin{array}{l}\text { Do you agree with banning smoking } \\
\text { in public areas? }\end{array}$} \\
\hline Yes & 308 & 81.1 & $34(11.0)$ & 274 (89.0) & 2.651 & 0.113 \\
\hline No & 72 & 18.9 & $13(18.1)$ & 59 (81.9) & & \\
\hline
\end{tabular}


negative attitudes towards allowing children to smoke in the future compared to non-smokers $(77.8 \%$ and $22.2 \%$, respectively, $\mathrm{p}<0.001$ ). Most of the smokers would allow smoking in their household compared to non-smokers $(64.3 \%$ vs $35.7 \%$, p<0.001).

\section{DISCUSSION}

In this study, the percentage of the prevalence of smoking among college students in rural areas was found to be $12.4 \%$. This prevalence was higher than the prevalence rate in some equivalent studies conducted on ages ranging from 18 to 28 years in Iran $(9.8 \%)^{18}$.

On the other hand, the prevalence rate was lower compared with the results from similar studies in Arab countries conducted among health-related students, including $46 \%$ in Kuwait ${ }^{19}, 17.2 \%$ in Jordan $^{20}, 46.7 \%$ in Egypt ${ }^{21}$ and 26.3\% in Lebanon ${ }^{22}$.

In terms of smoking prevalence among males and females, the conclusions from this study are that cigarette smoking was higher for males than females, $10.3 \%$ vs $2.7 \%$, a result in agreement with previous studies that reported on some Arab countries, such as the $\mathrm{KSA}(32.7 \% \text { vs } 5.9 \%)^{23}$ and the UAE $(84.6 \%$ vs $15.4 \%)^{24}$.

The study revealed that a greater proportion of females were waterpipe smokers compared to male smokers (13.0\% vs $0.0 \%)$. Similarly, a previous study conducted in Jordan concluded that the prevalence of waterpipe smokers was higher among females than males $(88.6 \% \text { vs } 36.6 \%)^{25}$. A Palestinian study also revealed a high rate of waterpipe smoking among female university students ${ }^{26}$. The prevalence of waterpipe smoking is predominant among female students. This reflects the fact that cigarette smoking is being replaced by waterpipe use, which is considered as an aspect of a modern lifestyle or prestige among the youth of the Eastern Mediterranean region ${ }^{27,28}$. This may be attributed to the fact that cigarette smoking is regarded as inappropriate behaviour for women in Yemeni culture, unlike waterpipe smoking which is quite tolerated and socially accepted and seen in common social interactions, such as gatherings and household meetings in Arab societies, giving waterpipe smoking the privilege of being socially accepted as part of the cultural heritage.

Based on statistical analysis, smoking prevalence was highly influenced by residence, as the rate was
$23.2 \%$ for students living in dormitories and $8.5 \%$ for those living with their families, in agreement with the findings of a similar study in Syria ${ }^{29}$. Gfroerer et al. ${ }^{30}$ also came to the conclusion that college students in the US who lived with their parents were less likely to smoke than students who did not. The reason may be that students who live with their families are less socially, emotionally and psychologically stressed than those who live abroad in dormitories and hence more susceptible to smoking. Another reason may be friends, as indicated also by previous studies on medical students in Japan and Albania; these studies reported that friends were the most important factor associated with smoking behaviours ${ }^{31,32}$.

In the current study, the prevalence rate of smoking was significantly affected by family income, that is, the percentage of smokers among students from low income families was higher than those from average and high income ones $(15.9 \%, 10.8 \%$, and $3.2 \%$, respectively); this finding was found to be in conformity with the world health survey, which stated that the poorest men were over 2.5 times more likely to smoke than the richest men in numerous countries $^{33}$. A possible reason also could be that students with a lower socioeconomic status had more physical, psychosocial and emotional problems.

Peer pressure and recreation were found to be the main reasons for students becoming involved in smoking, while 'proving manhood' was a major reason for non-smokers' attitudes, according to this study; similar findings were reported by previous studies ${ }^{34}$.

In this study, the attitudes of smoking and nonsmoking students towards smoking were contrasted; smokers were more tolerant of smoking at home and would be less likely to put pressure on their children not to smoke. Smokers were also less enthusiastic about prohibiting smoking in public places. Moreover, they had more negative attitudes with regard to allowing children to smoke in the future and allowing smoking in the household. Similar findings were obtained by a study in Palestine ${ }^{34}$.

The reasons for smoking identified in this study should be taken into account in the adoption of antismoking programmes, which could make them more effective and better able to influence the attitudes and behaviours of smokers. The study provides implications for policy makers. The ministry of education and higher education should apply anti-smoking programmes in 
all universities. Programmes need to be established that involve teenagers and youths as educators, and they should be supplied with correct and suitable information about the health consequences of smoking to educate the community. In addition, the media can assist in publicizing the anti-smoking messages to the whole population in Yemen.

\section{Strengths and limitations}

This study was the first student-based survey on the prevalence of smoking and its associated factors on students of health-related departments at a community college in the Hajja province of Yemen. It demonstrated the prevalence of smoking among students and associated factors in a rural area of Yemen. The study covered three health-related departments out of seven in the community college in a rural area. Hence, the results can be generalized to similar areas with similar social characteristics.

We believe our study has some limitations. First, since it was a cross-sectional study, the reported findings might be affected by reporting bias and the data may reflect respondents' subjective perceptions. Second, since the studied sample size of students from the rural area of the Hajja province was not relatively large, the applicability of the results to urban areas may be limited. Third, we did not examine the effects of cigarette and waterpipe smoking on rural areas. Hence, further studies are needed to clarify the effects of all kinds of smoking in the rural areas of Yemen.

\section{CONCLUSIONS}

The prevalence of smoking among college students in the rural area of the current study was found to be lower than that released by the WHO report ${ }^{12}$ of 2017 .

This study also revealed that male students were cigarette smokers, while females were waterpipe smokers. The prevalence of waterpipe users among females, as opposed to males, is a matter of concern. Factors such as sex, residence and family income were strongly associated with smoking prevalence. Youth from both genders have an ongoing attraction to cigarettes and waterpipes. An indication of a growth in tobacco use can be concluded. This necessitates the development of smoking cessation programmes, awareness raising and the promotion of anti-smoking attitudes in schools, colleges and universities in the region. Adopting anti-smoking programmes to prevent the harmful effects of smoking are urgently required in these colleges. Information on tobacco control policies should be widely disseminated.

\section{REFERENCES}

1. World Health Organization. WHO Report on the Global Tobacco Epidemic, 2011: Warning about the Dangers of Tobacco. http://www. who.int/ tobacco/global_ report/2011/ appendix_vii/en/index.html. Published, 2011. Accessed July 21, 2017.

2. World Health Organization. Combating the tobacco epidemic. In: World Health Organization, ed. Making a difference in people's lives. Geneva: World Health Organization; 1999.

3. Fakhfakh R, Hsairi M, Maalej M, Achour N, Nacef T. Tobacco use in Tunisia: behaviour and awareness. Bull World Health Organ. 2002;80:350-356.

4. Maziak W, Ward KD, Afifi Soweid RA, Eissenberg T. Tobacco smoking using a waterpipe: a re-emerging strain in a global epidemic. Tob Control. 2004;13:327333. doi:10.1136/tc.2004.008169

5. World Health Organization. WHO Report on the Global Tobacco Epidemic, the manpower package. Geneva: World Health Organization; 2008.

6. The global youth tobacco survey collaborative group. Tobacco use among youth: a cross-country comparison. Tob Control. 2002;11:252-270. doi:10.1136/tc.11.3.252

7. Hill Rice V, Weglicki L, Kulwicki A, Jamil H, Baker O. Arab American adolescent tobacco use. New Orleans, SRNT, 2003.

8. Jradi H, Wewers ME, Pirie PR, Binkley PF, Ferketich K. Cigarette and waterpipe smoking associated knowledge and behaviour among medical students in Lebanon. EMHJ. 2013;19:861-868. doi:10.26719/2013.19.10.861

9. Khabour OF, Alzoubi KH, Eissenberg T, et al. Waterpipe tobacco and cigarette smoking among university students in Jordan. Int J Tuberc Lung Dis. 2012;16:986992. doi:10.5588/ijtld.11.0764

10. World Health Organization. Health Statistics 2012. http:// www.who.int/gho/publications/world_health_statistics/ EN_WHS2012_Full.pdf. Accessed July 21, 2017.

11. Global Adult Tobacco Survey: GATS Qatar 2013 fact sheet. Doha: Government of Qatar.

12. WHO report on the global tobacco epidemic, 2017. http://www.who.int/tobacco/ surveillance/ policy/ country profile/yem.pdf. Accessed July 21, 2017.

13. World Health Organization. Global Youth Tobacco Survey (GYTS). http://www.who. int/ tobacco/surveillance/ gyts/en/. Accessed July 21, 2017.

14. World Health Organization. WHO/CDC Global Health Professional Survey (GHPS). http:// www.who.int/ tobacco/surveillance/ ghps/en/. Accessed July 21, 2017.

15. Maziak W, Ward KD, Soweid RA, Eissenberg T. Standardizing 
questionnaire items for the assessment of waterpipe tobacco use in epidemiological studies. Public Health. 2005;119(5):400-404. doi:10.1016/j.puhe.2004.08.002

16. World Health Organization. Guidelines for controlling and monitoring the tobacco epidemic. Geneva: World Health Organization; 1998.

17. World Bank Country and Lending Groups. https:// datahelpdesk. worldbank.org/knowledgebase/ articles/906519-world-bank-country-and-lendinggroups. Published, 2016. Accessed July 21, 2017.

18. Taheri E, Ghorbani A, Salehi M, Sadeghnia HR. Cigarette Smoking Behavior and the Related Factors Among the Students of Mashhad University of Medical Sciences in Iran. Iranian Red Crescent Medical Journal. 2015;17(1). doi:10.5812/ircmj.16254

19. Husain H, Al-Fadhli F, Al-Olaimi F, et al. Is smoking shisha safer than cigarettes: comparison of health effects of shisha and cigarette smoking among young adults in Kuwait. Medical Principles and Practice. 2016;25(2):117-122. doi:10.1159/000442417

20. Alomari Q, Barrieshi-Nusair K, Said K. Smoking prevalence and its effect on dental health attitudes and behavior among dental students. Medical Principles and Practice. 2006;15(3):195-199. doi:10.1159/000092181

21. Khan AA, Dey S, Taha AH, et al. Attitudes of Cairo University medical students toward smoking: the need for tobacco control programs in medical education. The Journal of the Egyptian Public Health Association. 2012;87:1. doi:10.1097/01.epx.0000411467.14763.0b

22. Jradi H, Wewers ME, Pirie PR, Binkley PF, Ferketich K. Cigarette and waterpipe smoking associated knowledge and behaviour among medical students in Lebanon. Eastern Mediterranean Health Journal. 2013;19:861868. doi:10.26719/2013.19.10.861

23. Mandil A, BinSaeed A, Ahmad S, Al-Dabbagh R, Alsaadi M, Khan M. Smoking among university students: a gender analysis. Journal of Infection and Public Health. 2010;3(4):179-187. doi:10.1016/j.jiph.2010.10.003

24. Mandil A, Hussein A, Omer H, Turki G, Gaber I. Characteristics and risk factors of tobacco consumption among University of Sharjah students, 2005. Eastern Mediterranean Health Journal. 2007;13(6). doi:10.26719/2007.13.6.1449

25. Obeidat SR, Khabour OF, Alzoubi KH, et al. Prevalence, social acceptance, and awareness of waterpipe smoking among dental university students: a cross sectional survey conducted in Jordan. BMC research notes. 2014;7(1):832. doi:10.1186/1756-0500-7-832

26. Palestinian Central Bureau of Statistics. Youth in Palestinian territory: statistical indicators. On the occasion of the International Youth Day 12 August 2008. http://www. pcbs.gov.ps/Portals/_pcbs/PressRelease/ shabab2008.pdf. Accessed July 21, 2017.

27. WorldHealthOrganization. WHOreportontheglobaltobacco epidemic, 2013. Enforcing bans on tobacco advertising, promotion and sponsorship. http://apps.who.int/iris/ bitstream/handle/10665/85380/9789241505871_eng. pdf? sequence=12013. Published, 2013. Accessed July 21, 2017.

28. Chaaya M, Jabbour S, El-Roueiheb Z, Chemaitelly H. Knowledge, attitudes, and practices of argileh (water pipe or hubble-bubble) and cigarette smoking among pregnant women in Lebanon. Addict Behav. 2004;29:1821-1831. doi:10.1016/j.addbeh.2004.04.008

29. Al-Kubaisy W, Abdullah NN, Al-Nuaimy H, Halawany G, Kurdy S. Epidemiological study on tobacco smoking among university students in Damascus, Syrian Arab Republic. Eastern Mediterranean Health Journal. 2012;18(7):723. doi:10.26719/2012.18.7.23

30. Gfroerer JC, Greenblatt JC, Wright DA. Substance use in the US college-age population: differences according to educational status and living arrangement. American Journal of Public Health. 1997;87:62-65. doi:10.2105/ajph.87.1.62

31. Majidpour A, Hamidzadeh Arbaby Y, Abbasgholizadeh $\mathrm{N}$, Salehy E. Prevalence and causes of tendency to cigarette smoking among students in Ardabil University of Medical Sciences. Journal of Ardabil University of Medical Sciences. 2005;(5)3:266-270.

32. Sejr HS, Osler M. Do smoking and health education influence student nurses' knowledge, attitudes, and professional behavior? Preventive Medicine. 2002;34:260-265. doi:10.1006/pmed.2001.0981

33. Hosseinpoor A.R., Parker L.A., Tursan d'Espaignet E., Chatterji S. Socioeconomic inequality in smoking in lowincome and middle-income countries: Results from the World Health Survey. PloS one. 2012 Aug 29; 7(8):e4284.

34. Musmar S.G. Smoking habits and attitudes among university students in Palestine: a cross-sectional study. Eastern Mediterranean Health Journal. 2012;18(5):454. doi:10.26719/2012.18.5.454

ACKNOWLEDGEMENTS

We express our gratitude to Professor Zhang Xinping for her tireless and continuous support for the success of this paper and her insight on how to carry it out.

CONFLICTS OF INTEREST

Authors have completed and submitted the ICMJE Form for Disclosure of Potential Conflicts of Interest and none was reported.

FUNDING

There was no source of funding for this research.

PROVENANCE AND PEER REVIEW Not commissioned; externally peer reviewed. 